\title{
Effect of internal mixture on black carbon radiative forcing
}

\author{
By CHUL E. CHUNG*, KYUNGHWA LEE AND DETLEF MÜLLER, Department of \\ Environmental Science and Engineering, Gwangju Institute of Science and Technology, Gwangju 500-712, Korea
}

(Manuscript received 10 June 2011; in final form 3 August 2011)

\begin{abstract}
The effects of coating on black carbon (BC) optical properties and global climate forcing are revisited with more realistic approaches. We use the Generalized Multiparticle Mie method along with a realistic size range of monomers and clusters to compute the optical properties of uncoated BC clusters. Mie scattering is used to compute the optical properties of $\mathrm{BC}$ coated by scattering material. When integrated over the size distribution, we find the coating to increase $\mathrm{BC}$ absorption by up to a factor of 1.9 (1.8-2.1). We also find the coating can significantly increase or decrease $\mathrm{BC}$ backscattering depending on shell size and how shell material would be distributed if $\mathrm{BC}$ is uncoated. The effect of coating on $\mathrm{BC}$ forcing is computed by the Monte-Carlo Aerosol Cloud Radiation model with observed clouds and realistic BC spatial distributions. If we assume all the $\mathrm{BC}$ particles to be coated, the coating increases global $\mathrm{BC}$ forcing by a factor of 1.4 from the $1.9 \times$ absorption increase alone. Conversely, the coating can decrease the forcing by up to $60 \%$ or increase it by up to $40 \%$ by only the BC backscattering changes. Thus, the combined effects generally, but not necessarily, amplify BC forcing.
\end{abstract}

Keywords: aerosol; black carbon; mixture; coating; forcing

\section{Introduction}

Black carbon (BC) aerosols are known to be a global warming agent (Ramanathan and Carmichael, 2008). The global and annual average of $\mathrm{BC}$ radiative forcing at the top of the atmosphere (TOA) is an important issue because reducing $\mathrm{BC}$ emission could be a powerful tool to combat global warming (Jacobson, 2001; Sato et al., 2003; Ramanathan and Carmichael, 2008). Published aerosol model $\mathrm{BC}$ radiative forcing estimates range widely from 0.2 to $0.8 \mathrm{~W} \mathrm{~m}^{-2}$ (Jacobson, 2001; Foster et al., 2007; Kim et al., 2008; Bond et al., 2011), whereas observationconstrained estimates (Sato et al., 2003; Ramanathan and Carmichael, 2008) give total (natural + anthropogenic) forcing about $0.9-1.0 \mathrm{~W} \mathrm{~m}^{-2}$. Assuming that $85 \%$ of BC total forcing is anthropogenic (Bond et al., 2011), it appears that model-based estimates tend to significantly underestimate $\mathrm{BC}$ forcing compared to observation-constrained ones.

One of the issues involved in understanding the wide range in the model-based estimates is whether the calculation considers $\mathrm{BC}$ to be internally mixed or externally

\footnotetext{
*Corresponding author. email: eddy@gist.ac.kr
}

mixed with other aerosols. Internal mixing is a $\mathrm{BC}$ particle and a non-BC particle existing together in a complete mixture, coating or attachment. Studies (e.g., Moffet and Prather, 2009) have shown that BC particles commonly exist in the ambient atmosphere as coated by scattering material such as sulphates, organics and nitrates. Many of the model-based estimates treat $\mathrm{BC}$ as $100 \%$ externally mixed with other aerosols (Textor et al., 2006), and with this type of mixing, the $\mathrm{BC}$ forcing is estimated to be smaller (Jacobson, 2001).

How much does the coating amplify BC forcing? Jacobson (2000) simulated that the coating of BC by scattering material increases $\mathrm{BC}$ forcing, and attributed this forcing increase to amplified solar radiation absorption by coating. Past studies (Schnaiter et al., 2005; Moffet and Prather, 2009) have clearly established that BC absorption is enhanced by a scattering material coating. The scattering shell acts as a lens and directs more photons to the BC core. Bond et al. (2006), using theoretical calculations, proposed that, at realistic shell sizes, BC absorption is enhanced by about $50 \%$. In the study by Jacobson (2001), $\mathrm{BC}$ forcing was amplified by a factor of 2 when most (not all) of the BC particles are coated. If all the BC particles were coated, the forcing would have been increased by more than a factor of 2. Can absorption 
enhancement by up to $50 \%$ indeed enhance the $\mathrm{BC}$ forcing by more than a factor of 2 ?

The objectives of this study are (a) to calculate absorption and scattering change when $\mathrm{BC}$ is coated; (b) to estimate the amplification of $\mathrm{BC}$ forcing by coating and (c) to understand the $\mathrm{BC}$ forcing amplification in previous model studies (e.g., Jacobson, 2000, 2001) where BC was treated as a spherical particle. Bond et al. (2006) calculated the absorption change by coating, and we revisit their work with more accuracy. The scattering change by coating needs to be defined. If $\mathrm{BC}$ is coated by sulphate, for example, can the scattering change by coating be all attributed to $\mathrm{BC}$ ? In the absence of $\mathrm{BC}$, the sulphate shell material would have remained as an independent sulphate particle (in case sulphate coating occurs by coagulation), condensed on another sulphate aerosol and nucleated a new sulphate aerosol, etc. The difference between the two situations should be and is used here to define BC scattering, as was the case in Jacobson $(2000,2001)$. In other words, the scattering of BC + sulsulphate combined particles will not be considered as $\mathrm{BC}$ scattering in the present study. The $\mathrm{BC}$ scattering for coated $\mathrm{BC}$ means here the scattering for coated $\mathrm{BC}$ minus that for scattering material in the absence of $\mathrm{BC}$. We note that in many studies (e.g., Kim et al., 2008) $\mathrm{BC}$ scattering, in case of $\mathrm{BC}$ coated by sulphate, refers to the scattering for the $\mathrm{BC}+$ sulphate combined particles.

Although coating increases $\mathrm{BC}$ absorption, it is not clear if coating also increases BC scattering, given our definition of $\mathrm{BC}$ scattering. Black carbon forcing at the TOA depends not only on $\mathrm{BC}$ absorption but also on $\mathrm{BC}$ backscattering. To understand this issue better, we discuss a pioneering study by Atwater (1970) who presented an analytical formula based on idealised earth conditions for how aerosol scattering and absorption affect the planetary albedo. The formula (4) presented in his paper is simplified to the following:

Planetary albedo change $=$

aerosol absorption $\times(1-\alpha)-$ aerosol backscattering $\times \alpha$,

where $\alpha$ is a function of surface albedo and atmosphere. Aerosol absorption alone reduces the planetary albedo and creates a warming effect. Aerosol backscattering, on the other hand, creates a cooling effect. Later, Chýlek and Wong (1995), among others, introduced a more realistic analytical formula. Hypothetically, if the coating increases backscattering enough to overcome the absorption enhancement effect, $\mathrm{BC}$ forcing might decrease after particle coating. Thus, it is safe to say that the effect of coating on BC TOA forcing is yet to be established.

Please note that throughout the text we refer to BC absorption/scattering/forcing as the change from a hypothetical no-BC atmosphere to the ambient atmosphere. This definition is a rephrase of the aforementioned definition and is consistent with the $\mathrm{BC}$ emission perspective. If $\mathrm{BC}$ emission is turned off, the scattering shell material would exist as other aerosols or parts of other aerosols. In this study, we quantify $\mathrm{BC}$ absorption and backscattering for uncoated $\mathrm{BC}$ cluster particles and for coated $\mathrm{BC}$, and thus quantify the effect of coating on $\mathrm{BC}$ absorption and $\mathrm{BC}$ backscattering. We rely on theoretical calculations because it is very difficult to quantify $\mathrm{BC}$ backscattering in experiments when $\mathrm{BC}$ is coated. We then implement the computed $\mathrm{BC}$ absorption and backscattering changes into a realistic radiation model with observed clouds to see how much the coating affects $\mathrm{BC}$ forcing. Section 2 discusses the optical properties of uncoated BC. In Section 3, we discuss BC optical properties for coated $\mathrm{BC}$, and the $\mathrm{BC}$ forcing computation follows in Section 4. The summary and discussions are in Section 5. Table 1 summarizes acronyms used in this paper.

\section{Optical properties of BC cluster}

\subsection{What is $B C$ ?}

Soot, emitted during incomplete combustion of hydrocarbons, quickly evolves into aggregates of fine particles in the ambient atmosphere (Katrinak et al., 1993) and is blackish in colour (Moosmüller et al., 2009). The fine particles, called spherules or monomers, are commonly in the range of $20-60 \mathrm{~nm}$ in diameter (Alexander et al., 2008). Transmission Electron Microscopy (TEM) images show that $\mathrm{BC}$ particles exist in cluster form containing multiple monomers (Alexander et al., 2008; Tumolva et al., 2010). The soot aggregates were called soot carbon by

Table 1. Summary of acronyms and key clarifications

Effect of coating on black Present study: BC coated by carbon (BC) optical properties scattering material vs. $\mathrm{BC}$ externally mixed with scattering aerosol. In most studies (e.g., Kim et al., 2008; Xue et al., 2009), BC coating effect refers to coated $\mathrm{BC}$ vs. stand-alone BC.

\begin{tabular}{ll}
\hline ABP & Absorption \\
BSCA & Backscattering \\
CMD & Count median diameter \\
GSD & Geometric standard deviation \\
$\mathrm{D}_{\mathrm{f}}$ & Fractal dimension \\
$\mathrm{K}_{\mathrm{f}}$ & Fractal prefactor \\
CDLA & Cluster-cluster diffusion-limited \\
& aggregation \\
\hline
\end{tabular}


Andreae and Gelencsér (2006), and in our study, we refer to them as $\mathrm{BC}$, as is the case in $\mathrm{BC}$ climate forcing studies. Fig. 1a is a visual of a typical BC cluster particle.

\subsection{BC clustering}

Black carbon is commonly treated as a spherical particle in global aerosol models (Jacobson, 2001; Kim et al., 2008; Myhre et al., 2008), despite the fact that the scattering properties of aggregate particles differ a lot from those of spherical ones (Köylü and Faeth, 1994; Choi et al., 1995; Li et al., 2010). In a more realistic approach, the particles are usually assumed to be aggregates of point-attached (non-overlapping) monomers with the same diameter. Such BC aggregates, specified as fractal aggregates (Forrest and Witten Jr, 1979; Sorensen and Roberts, 1997; Sorensen, 2001), can be quantitatively described in term of the statistic scaling rule, in the form of:

$N=k_{f}\left(\frac{R_{g}}{a}\right)^{D_{f}}$,

where $N$ is the number of monomers in the aggregate, $a$ the monomer radius, $K_{f}$ the fractal prefactor, $D_{f}$ the fractal dimension and $R_{g}$ the radius of gyration. $K_{f}$ and $D_{f}$ are two key structure parameters of BC aggregates. $R_{g}$ is a measure of the overall spread of the monomers from their mass centre, given by:

$R_{g}^{2}=\frac{1}{N} \sum_{i=1}^{N}\left(\vec{r}_{i}-\vec{r}_{o}\right)^{2}$

where $\vec{r}_{i}$ denotes the position vector of the centre of each monomer, and $\vec{r}_{o}$ the mass centre of the aggregate.

An improved cluster-cluster diffusion-limited aggregation (CDLA) algorithm, developed by Filippov et al. (2000), is applied here to numerically generate BC aggregates. As one of the most realistic and flexible methods, the CDLA method is widely used to generate the configuration of $\mathrm{BC}$ aggregates with specified fractal parameters and number of monomers (Liu and Mishchenko, 2005; Liu and
Mishchenko, 2007; Li et al., 2010). Starting from a singlemonomer BC particle, the method generates larger aggregates iteratively by randomly adding two previous smaller ones, each individually following the statistic scaling rule. At each iteration step, the relative distance between the two smaller clusters is determined from eqs. 2 and 3 (Filippov et al., 2000) to ensure that the combined aggregates also satisfy the statistic scaling rule, whereas all the other geometrical factors, such as relative orientation, connecting points, are randomly chosen.

Two sets of fractal parameters of (1) $K_{f}=1.6$ and $D_{f}$ $=1.8$ and (2) $K_{f}=1.6$ and $D_{f}=2.4$ are chosen to generate fractal aggregates. Measurement studies (Katrinak et al., 1993; Nyeki and Colbeck, 1995) support $D_{f}=1.8$ for uncoated $\mathrm{BC}$ clusters in the ambient atmosphere. When $\mathrm{BC}$ is coated, the clusters collapse into a more concentrated form and become spherical like with larger fractal dimensions (Schnaiter et al., 2005). Thus, with thick shells, BC can be treated as a spherical particle for its optical properties (Schnaiter et al., 2005). Black carbon clusters with $D_{f}=2.4$ are addressed as well to give insights into the difference between ambient $\mathrm{BC}$ aggregates and spherical BC particles. Fig. 1a Fig. $1 \mathrm{~b}$ are the examples of the aggregates generated with the CDLA algorithm. Regarding $K_{f}$, TEM images usually show values larger than 2.0 (Brasil et al., 2000), whereas theory suggests values close to 1.2 (Sorensen and Roberts, 1997; Brasil et al., 2000). In our effort to match experimental results, $K_{f}$ of 1.6 is chosen for our baseline calculation because our method cannot handle larger values. In a sensitivity run, we also show the results based on $K_{f}$ of 1.2 .

\subsection{The Generalized Multiparticle Mie (GMM) method}

With great interest in calculating the optical properties of $\mathrm{BC}$ aggregates, a number of approximate and exact methods have been developed. The Rayleigh-DebyeGans (RDG) method, ignoring the multiple scattering within the aggregates, can roughly approximate the optical

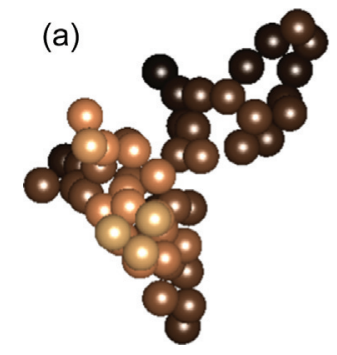

(b)

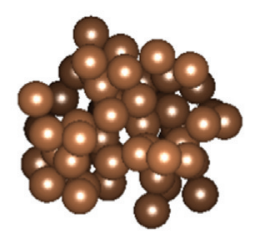

(c)

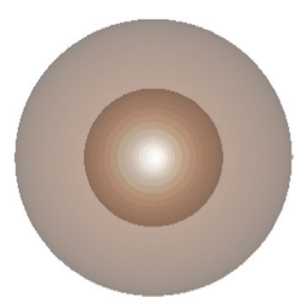

Fig. 1. Three particle shapes used in this study: (a) black carbon (BC) aggregate generated by the cluster-cluster diffusion-limited aggregation algorithm with a fractal prefactor of 1.6, and fractal dimension $\left(\mathrm{D}_{f}\right)$ of 1.8 ; (b) BC aggregate with $\mathrm{D}_{f}=2.4$; and $(\mathrm{c}) \mathrm{BC}$ sphere coated by scattering material. Black carbon in all of (a)-(c) has the same equivalent volume diameter. 
properties of $\mathrm{BC}$ aggregates without the configuration of aggregates. The RDG method was investigated and used in many past studies due to its simplicity and high efficiency (Farias et al., 1996; Sorensen, 2001; Alexander et al., 2008). In a study by Chakrabarty et al. (2007), errors made by the RDG approximation were shown to be $<10 \%$. Both the superposition T-matrix method (Liu and Mishchenko, 2005; Liu and Mishchenko, 2007; Liu et al., 2008) and GMM method (Van-Hulle et al., 2002; Li et al., 2010; Liu and Smallwood, 2010), known as exact methods available to compute the optical properties of $\mathrm{BC}$ aggregates, require an exact realization of the aggregates.

$\mathrm{Xu}(1995,1996,1997)$ and $\mathrm{Xu}$ and Gustafson (2001) developed the GMM method to deal with the scattering properties of the aggregates of spherical monomers with arbitrary numbers, sizes and refractive indices. The GMM method has been widely applied to calculate the scattering properties of soot aggregates (Van-Hulle et al., 2002; Li et al., 2010; Liu and Smallwood, 2010) and is used in this study.

Given a specified configuration of BC aggregates with aggregate size $N$ and monomer diameter $d$, the GMM method can simulate their optical properties. For each set of $N$ and $d, 20$ aggregates with different configurations are generated with the CDLA method, and their optical properties are averaged to give the ensemble-averaged properties of the aggregates. We simulate the optical properties of aggregates with 10 different aggregate sizes and four different monomer sizes. For aggregate size $N$; $5,10,20,30,40,55,70,100,150$ and 200 are used, and for monomer diameter $d ; 20,32,45$ and $60 \mathrm{~nm}$ are used. The computation is made at three different wavelengths, $\lambda=450,550$ and $700 \mathrm{~nm}$, and the refractive indices for $\mathrm{BC}$ at these wavelengths are set to $1.705+0.64 \mathrm{i}$, $1.8+0.71 \mathrm{i}$ and $1.895+0.78 \mathrm{i}$, respectively. We used Moffet and Prather's (2009) study for the refractive index at $550 \mathrm{~nm}$. The refractive indices at 450 and $700 \mathrm{~nm}$ were obtained by scaling Schnaiter et al.'s (2005) so that Schnaiter et al.'s index at $550 \mathrm{~nm}$ matches Moffet and Prather's. The sensitivity of the results to the refractive index will be addressed.

\subsection{Results}

Black carbon aerosols, once emitted, go through an ageing process whereby $\mathrm{BC}$ particles collide with each other (which affects the aggregate size) and other aerosols to become coated by other material. In the meantime, $\mathrm{BC}$ aerosols are transported and deposited on the surface. What is the size of an average $\mathrm{BC}$ particle over this journey? Alexander et al. (2008) measured BC aerosols over the Yellow Sea between China and Korea. The Yellow Sea is located at a mid-range distance downstream from the $\mathrm{BC}$ emission areas in China. Thus, BC aerosols measured by Alexander et al. (2008) are good candidates for the global average. According to Alexander et al. (2008), the median BC has 55 monomers with the monomer diameter being $32 \mathrm{~nm}$. If this $\mathrm{BC}$ cluster becomes a perfect sphere with an equal mass, the sphere diameter would be $122 \mathrm{~nm}$ that we call the 'equivalent volume diameter'. The equivalent surface area diameter of this particle, following the definition of $D_{p}$ in $\mathrm{Coz}$ and Leck (2011), is $237 \mathrm{~nm}$ that is very close to the median equivalent surface area diameter of $230 \mathrm{~nm}$ observed over the island of Hanimaadhoo near India (Coz and Leck, 2011).

We describe the size distribution of BC using a lognormal distribution function. The size of each aggregate particle is calculated using the equivalent volume diameter that is calculated as $2 \times a \times N^{1 / 3}$. In the log-normal function, the Count median (equivalent-volume) diameter

Table 2. Calculated optical properties of uncoated black carbon (BC) at $550 \mathrm{~nm}$, as averaged over a realistic size distribution. All the cases in this table have the same amount of BC volume. Black carbon refractive index is $1.8-0.71$ i. BSCA refers to backscattering

\begin{tabular}{|c|c|c|c|c|c|c|}
\hline & \multicolumn{3}{|c|}{ Integrated over a realistic range of monomer sizes } & \multicolumn{3}{|c|}{$\begin{array}{l}\text { With a single BC monomer diameter }\left(D_{m}\right) \\
\text { and for aggregates with } D_{f}=1.8 \& \\
\qquad K_{f}=1.6\end{array}$} \\
\hline & Perfect spheres & $\begin{array}{l}\text { Aggregates }\left(D_{f}=1.8\right. \\
\left.\quad \text { and } K_{f}=1.6\right)\end{array}$ & $\begin{array}{c}\text { Aggregates }\left(D_{f}=2.4\right. \\
\left.\text { and } K_{f}=1.6\right)\end{array}$ & $D_{m}=32 \mathrm{~nm}$ & $D_{m}=45 \mathrm{~nm}$ & $D_{m}=60 \mathrm{~nm}$ \\
\hline $\begin{array}{l}\text { EXT. cross section per } \\
\text { particle }\left(\mu \mathrm{m}^{2}\right)\end{array}$ & 2.89E-02 & $2.43 \mathrm{E}-02$ & 2.66E-02 & $1.28 \mathrm{E}-02$ & $2.30 \mathrm{E}-02$ & $3.68 \mathrm{E}-02$ \\
\hline ABP. cross section $\left(\mu \mathrm{m}^{2}\right)$ & $1.96 \mathrm{E}-02$ & $1.98 \mathrm{E}-02$ & $1.96 \mathrm{E}-02$ & $1.14 \mathrm{E}-02$ & $1.92 \mathrm{E}-02$ & 2.89E-02 \\
\hline SCA. cross section $\left(\mu \mathrm{m}^{2}\right)$ & $9.27 \mathrm{E}-03$ & 4.50E-03 & 7.00E-03 & $1.45 \mathrm{E}-03$ & $3.78 \mathrm{E}-03$ & 7.83E-03 \\
\hline BSCA. cross section $\left(\mu \mathrm{m}^{2}\right)$ & $3.21 \mathrm{E}-03$ & $1.15 \mathrm{E}-03$ & $1.86 \mathrm{E}-03$ & 4.30E-04 & $1.06 \mathrm{E}-03$ & 2.14E-03 \\
\hline ASY & 0.352 & 0.558 & 0.536 & 0.463 & 0.504 & 0.518 \\
\hline SSA & 0.321 & 0.185 & 0.264 & 0.113 & 0.164 & 0.213 \\
\hline
\end{tabular}

ASY, asymmetry parameter. 
(CMD) is set to $122 \mathrm{~nm}$, following Alexander et al.'s (2008) finding, and the Geometric standard deviation (GSD) is set to 1.5 . We will explore the sensitivity of the results to the CMD in the range of $100-140 \mathrm{~nm}$. We consider a realistic range of monomer size from 20 to $60 \mathrm{~nm}$ in diameter and a realistic range of the number of monomers from 5 to 200 . Table 2 shows the computed optical properties of $\mathrm{BC}$ cluster particles and of spherical BC particles, as averaged over the same aggregate size distribution. Spherical BC optical properties are calculated with a Mie scattering code. All the cases in Table 2 have the same CMD and GSD.

The results, as summarized in Table 2, reveal a number of new findings. A spherical $\mathrm{BC}$, compared to a $\mathrm{BC}$ cluster of $D_{f}=1.8$, has approximately the same amount of absorption and twice as much scattering. Bond et al. (2006) thought that a BC cluster would have 1.3 times as much absorption as spherical $\mathrm{BC}$ but our result does not support their speculation. We also find that the optical properties of a BC cluster of $D_{f}=1.8$ are dependent strongly on monomer size, despite the same cluster size. Clusters with higher $a$ and lower $N$ scatter and absorb much more than those with lower $a$ and higher $N$. We conclude that studies with a single monomer size significantly misrepresent the optical properties of BC clusters, and we prefer to use a realistic range of monomer sizes. As for the asymmetry parameter (ASY) that is not very sensitive to monomer size, the spherical $\mathrm{BC}$ has a lower ASY than the BC cluster of $D_{f}=1.8$. Compared to BC clusters, spherical BC particles have a higher single scattering albedo (SSA) and lower ASY. Another way to understand this is that spherical BC has more backscattering than clustered $\mathrm{BC}$. Because increased backscattering lowers BC TOA forcing (see eq. 1), treating BC as spherical will lead to underestimated $\mathrm{BC}$ forcing in models.

Table 3 shows the $\mathrm{BC}$ optical properties when $K_{f}$ is lowered from 1.6 to 1.2. Although changes in optical property are small, it is interesting to note that BC SSA becomes lower.

Table 3. Same as in Table 2 except for different $K_{f}$

\begin{tabular}{lc}
\hline & $\begin{array}{c}\text { Integrated over a realistic range of } \\
\text { monomer sizes }\end{array}$ \\
\cline { 2 - 2 } & $\begin{array}{c}\text { Aggregates }\left(D_{f}=1.8 \text { and } K_{f}=1.2\right) \\
\text { EXT. cross section per }\end{array}$ \\
$\quad$ particle $\left(\mu \mathrm{m}^{2}\right)$ & $2.39 \mathrm{E}-02$ \\
ABP. cross section $\left(\mu \mathrm{m}^{2}\right)$ & $2.01 \mathrm{E}-02$ \\
SCA. cross section $\left(\mu \mathrm{m}^{2}\right)$ & $3.87 \mathrm{E}-03$ \\
BSCA. cross section $\left(\mu \mathrm{m}^{2}\right)$ & $9.87 \mathrm{E}-04$ \\
ASY & 0.561 \\
SSA & 0.162 \\
\hline
\end{tabular}

ASY, asymmetry parameter.

\section{Optical properties of coated BC}

Schnaiter et al. (2005) demonstrated that the Mie scattering core-shell model accurately describes the optical properties of thickly coated BC particles. Moffet and Prather (2009) used the core-shell model to successfully explain the observed soot properties in the ambient atmosphere. Likewise, we use the core-shell model to compute the optical properties of coated $\mathrm{BC}$. When the shells are thin, the cluster structure of BC remains intact (Schnaiter et al., 2005; Adachi et al., 2010) and neither the GMM method nor the Mie core-shell model is appropriate. For such thinly coated BC, Adachi et al. (2010) showed that absorption enhancement by coating is less significant. We use this result to scale down the absorption enhancement calculated by the core-shell model, when the shells are thin.

As we apply the core-shell model, the core is treated as spherical. The size distribution of the core follows the same size distribution we used for uncoated BC in Section 2.4, where the BC particle size was defined with equivalent volume diameter. In other words, the core size distribution is simply assuming that the $\mathrm{BC}$ is coated and becomes spherical. We then coat the $\mathrm{BC}$ cores with shells and increase the shell size.

How will the shell size distribution be? Will small cores be associated with thin shells or thick shells? Or are shell sizes unrelated to core sizes? Homogeneous condensation (e.g., growth of pure sulphate particle by supersaturation) tends to grow small particles faster than large particles because $D_{\text {final }}^{2}=D_{\text {initial }}^{2}+2$ At (Seinfeld and Pandis, 1998); $D_{\text {initial }}$ refers to the diameter of the particle before condensation and $D_{\text {final }}$ refers to the diameter after condensation. If the $\mathrm{BC}$ coating occurs through condensation and also follows the above formula, small cores would have thicker shells than large cores. Conversely, if the coating occurs by coagulation, large cores will grow more rapidly. In reality, coagulation, condensation, dissolution, etc. will all take place.

As BC cores get coated and the coating becomes thicker, the CMD increases. If small cores grow faster than large cores, the GSD will decline. The laboratory experiments by Schnaiter et al. (2005) showed that GSD does decline but very slowly with growing shells (see Fig. 5 of their study between experiment 10th hour and 25th hour). This slow GSD decline with shell growth shown by Schnaiter et al. (2005) is between the two scenarios we have developed: (1) the shell sizes are the same for all the particles and (2) the ratio of shell to core size is the same for all the particles. In the second scenario, GSD does not change with shell size, as shown in Fig. 2. In the first scenario, GSD declines substantially (Fig. 2). We propose that between these two scenarios, they 


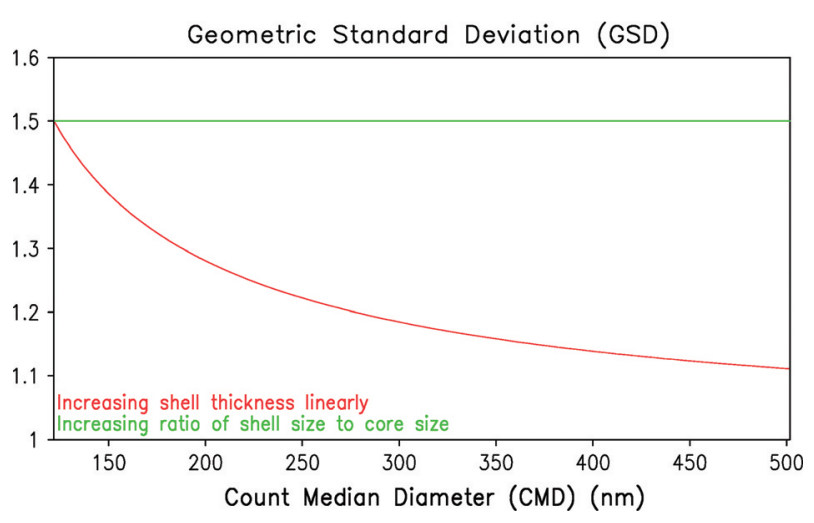

Fig. 2. GSD and CMD changes as the black carbon (BC) population is coated with increasing shells. With no shell, the CMD of $\mathrm{BC}$ is set to $122 \mathrm{~nm}$. Shells increase the CMD of the particles. When the shell size increases linearly (i.e., equal shell size for all the BC cores), GSD declines with shell size. When we increase the ratio of shell to core (i.e., equal ratio for all the particles) to increase shell size, GSD remains unchanged.

bracket all the realistic ways to grow shells in the ambient atmosphere.

Figure 3 a shows how BC absorption at $550 \mathrm{~nm}$ changes with growing shells. The BC absorption gets doubled when the CMD approaches $500 \mathrm{~nm}$. What is the realistic maximum size for coated BC? Moffet and Prather (2009), for example, looked at $\mathrm{BC}$ particles in cities and found that aged $\mathrm{BC}$ has less than twice as much $\mathrm{CMD}$ as fresh BC. Transported BC over a long distance is expected to be thickly coated. Schnaiter et al. (2005) grew shells until the CMD reached $400 \mathrm{~nm}$. In view of these studies, we argue that CMDs of $350-500 \mathrm{~nm}$ represent the realistic maximum sizes for coated BC. Our speculation, however, needs further support from ambient measurement studies. At realistic maximum shell sizes, coating increases BC absorption by a factor 1.9 . When we vary the core CMD from 100 to $140 \mathrm{~nm}$, and vary the BC refractive index (e.g., $1.9-1.0 \mathrm{i}$ from $1.8-0.71 \mathrm{i}$ at $550 \mathrm{~nm}$ ), we find that the amplification factor is between 1.8 and 2.1. This number is consistent with the laboratory study by Schnaiter et al. (2005). In reality, not every BC is coated and not every coated BC has a thick shell. Thus, the $1.9(1.8-2.1)$ time absorption increase should be taken as the upper limit. Note that the hatched area in Fig. 3 is an approximate range where the core-shell model is not expected to work well. We calculated this range based on Schnaiter et al.'s (2005) study. Over this range, the absorption enhancement calculated by the core-shell model should be revised downwards, given the finding by Adachi et al. (2010). (a) Absorption Cross Section Ratio

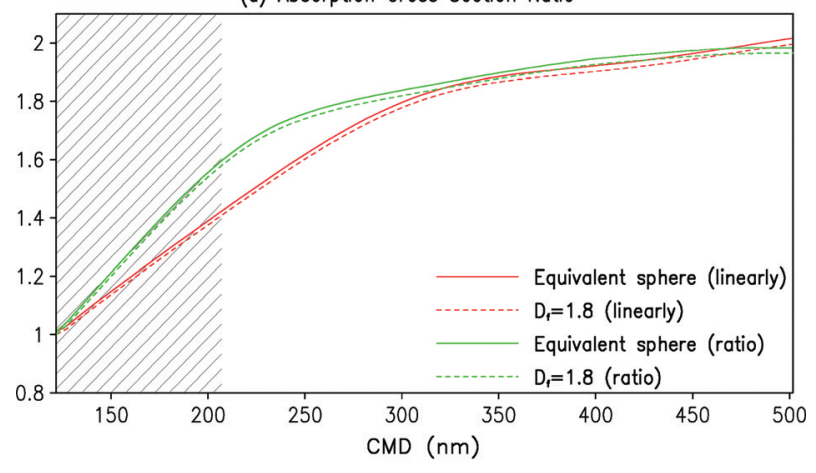

(b) Backscattering Cross Section Ratio (new particle creation scenario)

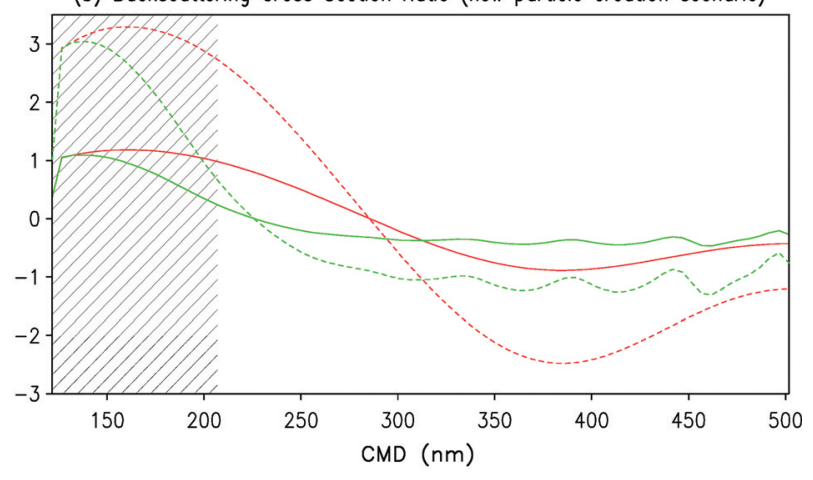

(c) Backscattering Cross Section Ratio (existing particle expansion scenario)

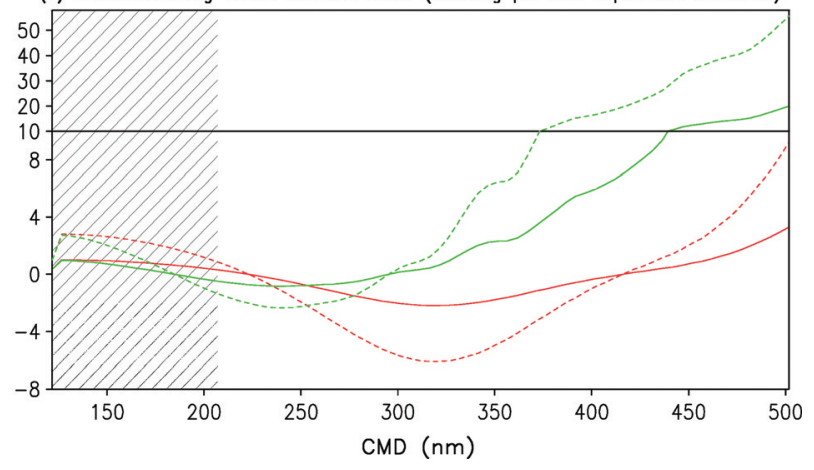

Fig. 3. (a) Ratio of absorption/backscattering cross-section for coated black carbon (BC) to that for uncoated $\mathrm{BC}+$ scattering aerosol, at $550 \mathrm{~nm}$. (b) 'New particle creation scenario' means that scattering shells create new scattering aerosols in the absence of BC. (c) 'Existing particle expansion scenario' is that scattering shells expand existing scattering aerosols instead of creating new particles. Red lines denote the coating experiment where the shells increase linearly; see Fig. 2 to understand 'linearly' and 'ratio'. Uncoated BC optical properties are calculated in two ways: Assuming cluster structure of $\mathrm{D}_{f}=1.8$ (dashed line) and spherical shape (solid line) of BC population. The results in the hatched region are not very accurate as the Mie scattering core-shell model does not work well in this range. The shell refractive index is $1.465+$ i0.0, as in Moffet and Prather (2009). 
The effect of increasing shells on $\mathrm{BC}$ backscattering is shown in Figs $3 b$ and c. Scattering material in the shells enhances the scattering and backscattering of the coated particles substantially, and this is shown in Fig. 4 for those that only consider the optical properties of the combined core-shell aerosols. Calculating BC backscattering for coated $\mathrm{BC}$ requires the backscattering in the absence of BC. Figure 3b follows Jacobson's (2000) approach, where the shell of a coated particle is used to make a new particle. This new particle is assumed to exist in the absence of BC. In reality, a portion of the scattering material surrounding $\mathrm{BC}$ cores would have condensed onto other scattering aerosols instead of making new particles. Fig. 3c represents an extreme hypothesis that all the scattering material surrounding $\mathrm{BC}$ cores would have condensed onto other scattering aerosols. In Fig. 3c, the other scattering aerosols are assumed to have the same CMD and GSD as the coated BC. The shells are used to expand existing scattering aerosols instead of making new particles, and the expanded aerosols are assumed to have the same population size as the coated $\mathrm{BC}$ particles. We develop these two scenarios to estimate the upper limit and the lower limit of $\mathrm{BC}$ backscattering change.

The backscattering ratio, as shown in Fig. $3 \mathrm{~b}$ and c, has the following meaning. When the ratio is $>1.0$, coating increases $\mathrm{BC}$ backscattering. When the ratio is between 1.0 and 0.0 , coating reduces $\mathrm{BC}$ backscattering. When the ratio is $<0.0$, coating reduces the $\mathrm{BC}$ backscattering to the point where coated $\mathrm{BC}$ has less backscattering than no BC. In other words, at a ratio $<0.0$, adding $\mathrm{BC}$ as cores decreases total aerosol backscattering. In the new particle creation scenario (Fig. 3b), the backscattering ratio is $<0.0$ over most of the shell thickness range. Against uncoated $\mathrm{BC}$ clusters, the backscattering ratio is between -1.0 and -2.0 with thick shells (see the dashed lines). In the existing particle expansion scenario (Fig. 3c), the backscattering ratio is between -5.0 and 10.0 or greater against uncoated $\mathrm{BC}$ clusters. By varying the core $\mathrm{CMD}$ or $\mathrm{BC}$ refractive index, we get a wider range of ratio. Taken together, $\mathrm{BC}$ backscattering can decrease or increase significantly, depending on shell size and whether the shells create new particles or expand existing scattering aerosols.

We also assess the effect of coating on Absorption Ångström Exponent (AAE) by extending absorption computation to 450 and $700 \mathrm{~nm}$. Black carbon AAE is commonly assumed to be 1.0 (e.g., Arola et al., 2011), despite Gyawali et al.'s (2009) theoretical study showing that BC AAE could be as low as 0.0 or even slightly negative due to either internal mixture or large particle size. (a) Scattering Cross Section Ratio

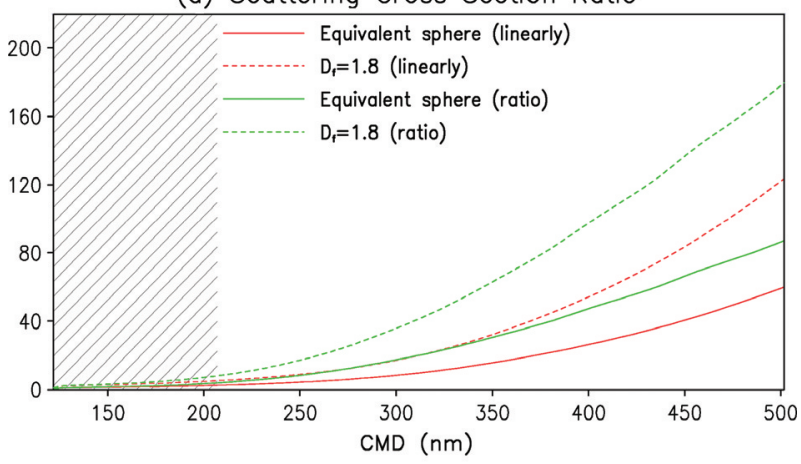

(b) Backscattering Cross Section Ratio

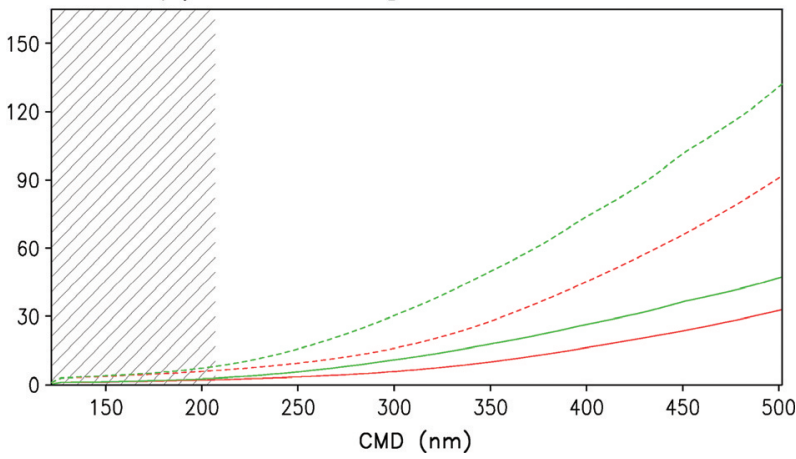

Fig. 4. Same as Fig. 3, except for the ratio of absorption/ backscattering cross-section for coated black carbon (BC) (i.e., $\mathrm{BC}+$ scattering material) to that for uncoated $\mathrm{BC}$ at $550 \mathrm{~nm}$.

Kirchstetter et al.'s (2004) study is the basis for the widely used value of 1.0 for BC AAE. Kirchstetter et al. (2004) proposed 1.0 from various measurements. The actual measurements showed $0.7-1.1$ for $\mathrm{BC}$ concentrated samples, and the samples were taken near emission sources. The uncoated BC clusters in this study have an AAE of 0.76 (Fig. 5). Coating generally lowers the AAE. With thick shells, the BC AAE becomes as low as 0.1. In view of this, we suspect that Kirchstetter et al.'s (2004) BC samples consisted of fresh $\mathrm{BC}$ and other absorbers in minor amounts.

\section{Global BC forcing}

We assess the effects of coating on global $\mathrm{BC}$ forcing at the TOA. An analytical solution such as the one developed by Atwater (1970) ignores spatial and vertical distributions of aerosol and cloud and should be considered as a rough approximation. To accurately quantify the coating effect on global $\mathrm{BC}$ forcing, we follow up on Chung et al.'s (2005) study. Chung et al. (2005) computed the total (natural + anthropogenic) aerosol forcing by (a) integrating 2001-2003 aerosol optical depth (AOD) 


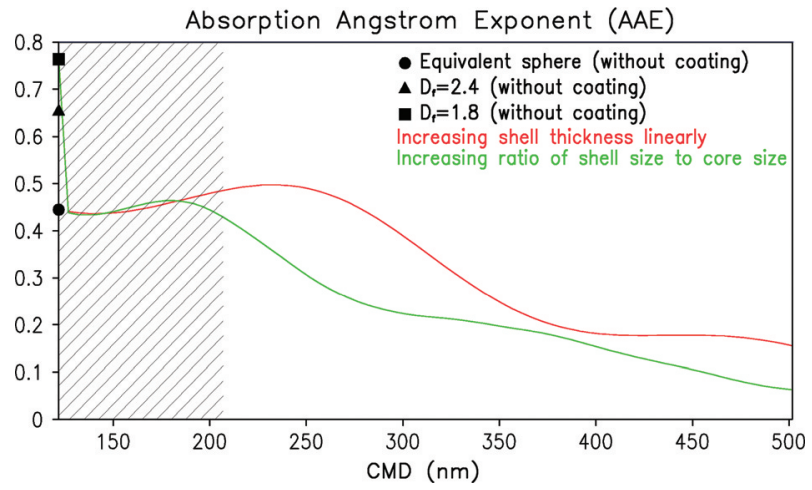

Fig. 5. Absorption Angstrom Exponent (AAE) of uncoated black carbon (BC) and coated BC. Closed symbols denote AAE of uncoated $\mathrm{BC}$, when $\mathrm{BC}$ is treated as spheres (circle), aggregates with $\mathrm{D}_{f}=2.4$ (triangle) and aggregates with $\mathrm{D}_{f}=1.8$ (square). Coated BC has two ways to increase shells; see Fig. 2 for details. The results in the hatched region are not very accurate as the Mie scattering core-shell model does not work well in this range.

from Aerosol Robotic Network (AERONET) and Moderate Imaging Spectro-radiometer (MODIS) sensors and (b) inserting the integrated aerosol observations into the Monte-Carlo Aerosol Cloud Radiation (MACR) model along with observed cloud effects. We update observed AODs with recently available datasets. To obtain the $\mathrm{BC}$ AOD, we calculate the ratio of $\mathrm{BC}$ AOD to total AOD simulated by the Georgia Tech/Goddard Global Ozone Chemistry Aerosol Radiation and transport (GOCART) model (Chin et al., 2002) and multiply the observed AOD climatology (2001-2009) with this ratio at each grid and calendar month.

\subsection{AOD update}

4.1.1. MODIS. MODIS is a satellite sensor on board the Terra and Aqua satellites. We downloaded Aqua and Terra M3 AODs at $550 \mathrm{~nm}$ that are monthly means of daily means. Terra AOD from February 2000 to February 2010 and Aqua AOD from July 2002 to February 2010 on the $1^{\circ} \times 1^{\circ}$ resolution were converted to monthly combined AOD on the T42 resolution by the following algorithm: If there are at least five values from either satellite in each T42 gridbox, a median is calculated to remove outliers. We then removed combined AODs that are larger than 0.28 north of $60^{\circ} \mathrm{N}$ and larger than 0.20 south of $30^{\circ} \mathrm{S}$. Eliminated AODs appeared unrealistic and were probably related to cloud contamination.

4.1.2. Multiangle Imaging Spectro-Radiometer (MISR) data. MISR is another satellite sensor. We downloaded the CGAS MIL3MAE.4 product from February 2000 to
December 2009. Out of this monthly product, we selected the $555 \mathrm{~nm}$ AOD and the Ångström exponent $(\alpha)$. The data were originally available on the $1^{\circ} \times 1^{\circ}$ resolution and were converted into the $\mathrm{T} 42$ resolution using a median method like the MODIS AOD. The $550 \mathrm{~nm}$ AOD was obtained by the following formula:

$\operatorname{AOD}(550)=\operatorname{AOD}(555 \mathrm{~nm})\left(\frac{550}{555}\right)^{-\alpha}$

4.1.3. AERONET. AERONET is a ground-based network that reports aerosol optical properties (Holben et al., 2001). AERONET offers a Version 2 product. We downloaded the monthly Level 2.0 from the Version 2 product for the period 2001-2009. In this dataset, values are preand post-field calibrated, cloud screened and quality assured. AERONET does not offer aerosol optical properties directly at $550 \mathrm{~nm}$. We obtained AOD at $550 \mathrm{~nm}$ by logarithmically interpolating the AOD from available values at nearby wavelengths.

4.1.4. Aerosol optical depth integration. The assimilation process takes place in three steps. (1) We fill the gaps in MODIS AOD with MISR AOD using the iterative difference-successive correction method developed by Cressman (1959). MODIS does not give AOD over desert areas where MISR offers AOD. (2) The remaining gaps in MODIS + MISR AOD are filled with GOCART AOD again using Cressman's (1959) method. (3) The spatial pattern in MODIS + MISR + GOCART AOD is coupled with the sparsely distributed AERONET AOD values, using Chung et al.'s (2005) technique.

\subsection{MACR model}

The MACR model was developed and validated during the INDOEX (Ramanathan et al., 2001) and Chung et al. (2005) updated the model. We use Chung et al.'s (2005) model with updated aerosol inputs. All the calculations are for solar radiation only.

\subsection{Modelling results}

Fig. 6a displays our BC AOD. The overall large-scale patterns appear consistent with the global patterns of $\mathrm{BC}$ emissions (Bond et al., 2004). The overall BC AOD magnitude may be questioned because the GOCART simulation determines most of it and aerosol models are subject to numerous error sources. To bypass this uncertainty, we focus on how the coating affects $\mathrm{BC}$ forcing in terms of ratio. To compute the forcing of externally 
(a) Annual-mean BC AOD

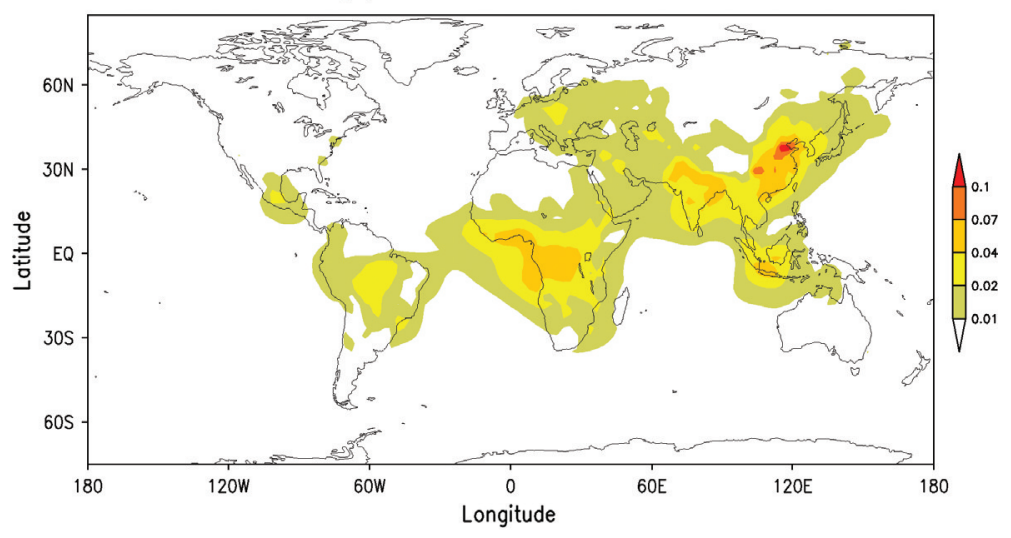

(b) Annual-mean BC forcing

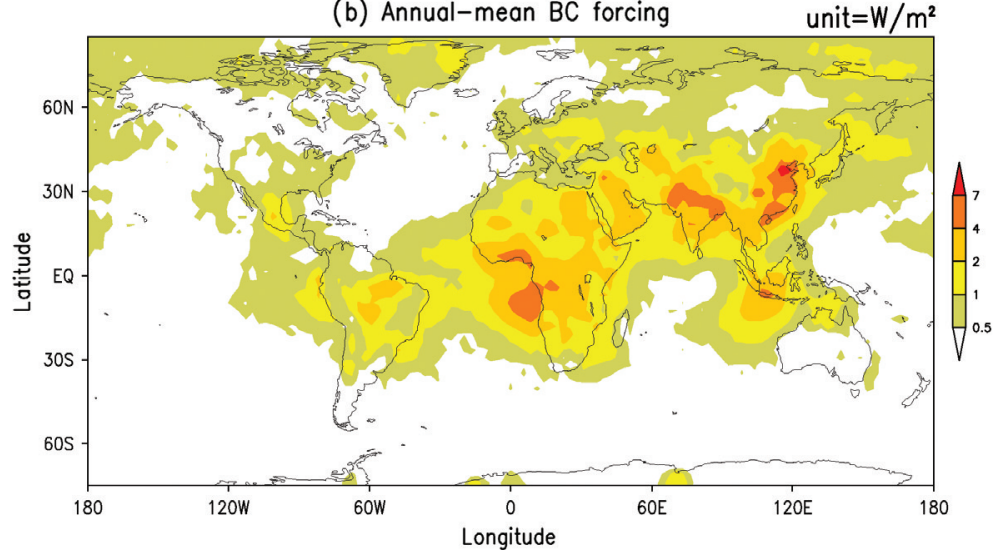

Fig. 6. Black carbon (BC) aerosol optical depth (AOD) and BC forcing, when BC is all externally mixed with other aerosols.

mixed BC, a BC SSA of 0.185 and ASY of 0.558 are used, adopting the $D_{f}=1.8$ values in Table 2. Fig. $6 \mathrm{~b}$ shows the annual-mean total (natural + anthropogenic)
$\mathrm{BC}$ forcing. For brevity, hereafter, $\mathrm{BC}$ forcing refers to total $\mathrm{BC}$ forcing. The global average $\mathrm{BC}$ forcing is $0.78 \mathrm{~W}$ $\mathrm{m}^{-2}$ (Table 4). This forcing reduces to $0.56 \mathrm{~W} \mathrm{~m}^{-2}$, when

Table 4. Simulated globally averaged annual-mean black carbon (BC) forcing (anthropogenic + natural)

\begin{tabular}{|c|c|c|c|c|c|c|c|}
\hline & \multirow[b]{2}{*}{$\begin{array}{l}\text { Externally } \\
\text { mixed BC }\end{array}$} & \multicolumn{6}{|c|}{ Coated BC } \\
\hline & & $\begin{array}{l}\mathrm{BC} \text { ABP } \\
\uparrow(\times 1.9)\end{array}$ & $\begin{array}{l}\text { BC BSCA } \\
\downarrow(\times 5.0)\end{array}$ & $\begin{array}{l}\text { BC BSCA } \\
\downarrow(\times 2.0)\end{array}$ & $\begin{array}{l}\text { BC BSCA } \\
\uparrow(\times 2.0)\end{array}$ & $\begin{array}{c}\mathrm{BC} \mathrm{BSCA} \uparrow \\
(\times 5.0)\end{array}$ & $\begin{array}{c}\mathrm{BC} \mathrm{BSCA} \uparrow \\
(\times 10.0)\end{array}$ \\
\hline TOA $\left(\mathrm{W} \mathrm{m}^{-2}\right)$ & 0.78 & 1.13 & 1.07 & 0.93 & 0.73 & 0.58 & 0.33 \\
\hline Atmosphere $\left(\mathrm{W} \mathrm{m}^{-2}\right)$ & 2.62 & 3.90 & 2.60 & 2.61 & 2.63 & 2.64 & 2.65 \\
\hline \multirow[t]{3}{*}{ Surface $\left(\mathrm{W} \mathrm{m}^{-2}\right)$} & -1.84 & -2.77 & -1.53 & -1.69 & -1.90 & -2.05 & -2.32 \\
\hline & & \multicolumn{4}{|c|}{ Coated BC } & & \\
\hline & $\begin{array}{l}\text { Externally } \\
\text { mixed BC }\end{array}$ & $\begin{array}{c}\text { BC ABP } \\
\uparrow(\times 1.9) \\
\& \text { BC BSCA } \\
\downarrow(\times 2.0)\end{array}$ & $\begin{array}{c}\mathrm{BC} \mathrm{ABP} \\
\uparrow(\times 1.8) \& \mathrm{BC} \\
\mathrm{BSCA} \downarrow(\times 5.0)\end{array}$ & $\begin{array}{c}\mathrm{BC} \text { ABP } \\
\uparrow(\times 1.9) \\
\& \mathrm{BC} \mathrm{BSCA} \\
\uparrow(\times 10.0)\end{array}$ & $\begin{array}{c}\mathrm{BC} \text { ABP } \\
\uparrow(\times 1.7) \& \mathrm{BC} \\
\mathrm{BSCA} \downarrow(\times 0.5)\end{array}$ & & \\
\hline TOA $\left(\mathrm{W} \mathrm{m}^{-2}\right)$ & 0.78 & 1.27 & 1.41 & 0.67 & 1.17 & & \\
\hline Atmosphere $\left(\mathrm{W} \mathrm{m}^{-2}\right)$ & 2.62 & 3.89 & 3.81 & 3.93 & 3.75 & & \\
\hline Surface $\left(\mathrm{W} \mathrm{m}^{-2}\right)$ & -1.84 & -2.61 & -2.40 & -3.25 & -2.57 & & \\
\hline
\end{tabular}

TOA, top of the atmosphere. 


\section{(a) BC forcing at TOA}

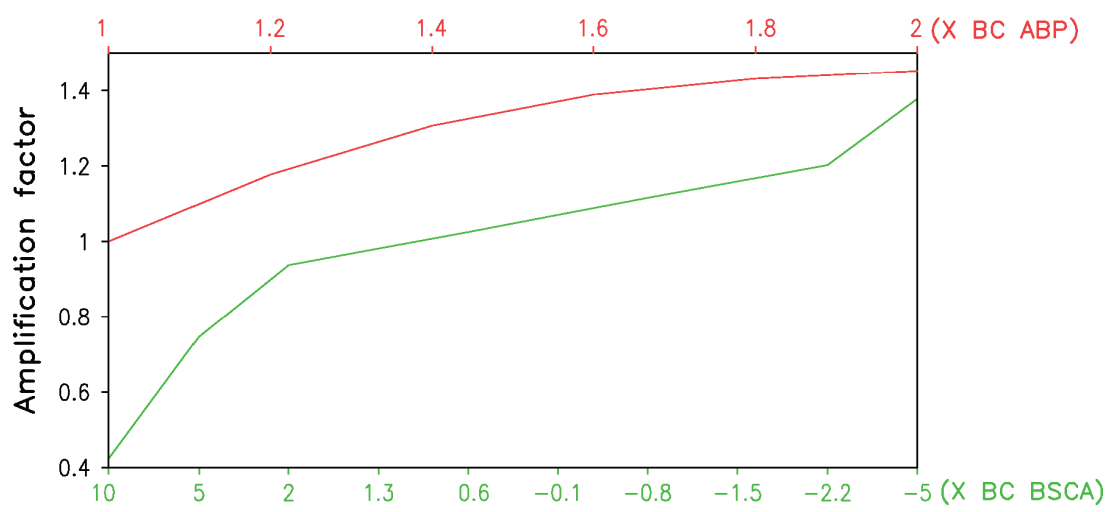

(b) $\mathrm{BC}$ forcing in the atmosphere

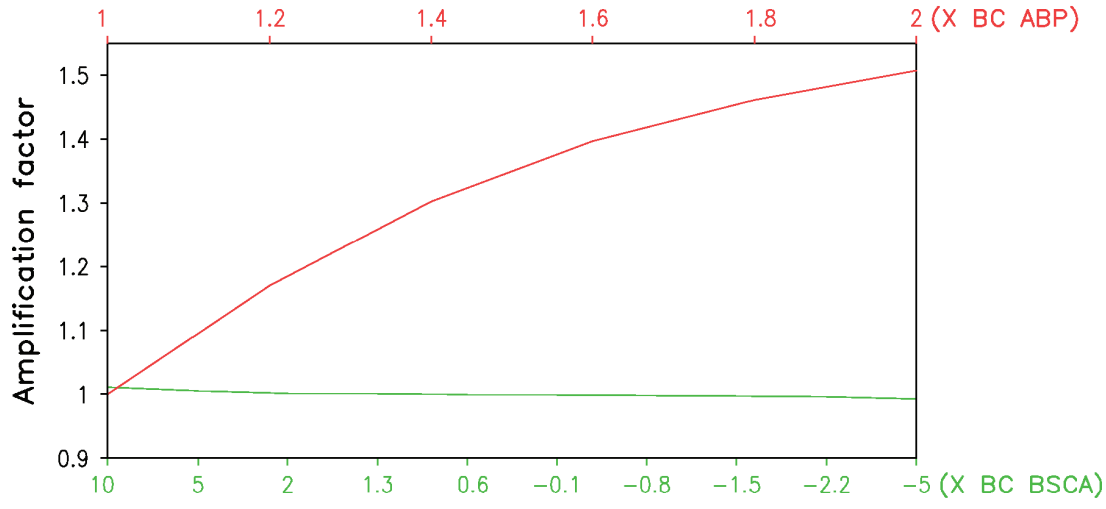

(c) BC forcing at surface

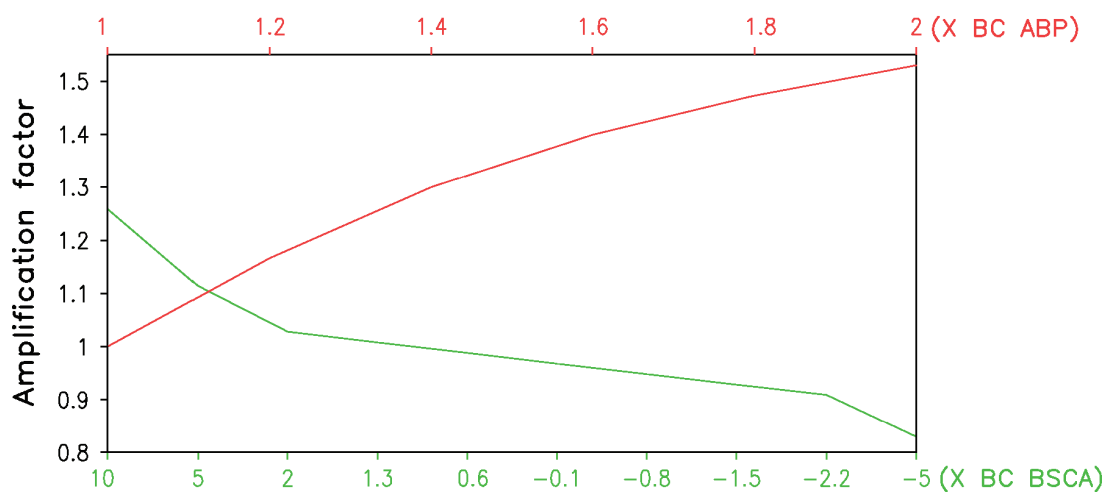

Fig. 7. Ratio of black carbon (BC) forcing for coated BC to that for uncoated BC: (a) at the top of the atmosphere (TOA), (b) in the atmosphere and (c) at the surface. Black carbon forcing for coated $\mathrm{BC}$ here means the forcing for coated $\mathrm{BC}$ minus the forcing for scattering aerosols; see Section 1 for clarification. In this definition, coating always increases BC absorption but may decrease BC backscattering. The experiments here demonstrate the separate effects of $\mathrm{BC}$ absorption increase and $\mathrm{BC}$ backscattering change.

the SSA and ASY for spherical BC are used. Thus, treating $\mathrm{BC}$ as spherical by itself reduces the $\mathrm{BC}$ forcing by $30 \%$.

The effect of coating on $\mathrm{BC}$ forcing is quantified in xtwo ways. In the first experiment, we increase BC absorption globally while retaining the BC backscattering.
In the second experiment, the absorption remains unchanged and we modify the BC backscattering. The absorption increase enhances global $\mathrm{BC}$ forcing as expected (Fig. 7). The realistic maximum of the $\mathrm{BC}$ absorption increase is 1.9 times, and this 1.9 time absorption increase 
leads to a 1.4 time increase in BC forcing (Table 4). The 1.9 time absorption increase amplifies the $\mathrm{BC}$ forcing in the atmosphere by a factor of 1.5 .

Black carbon backscattering changes can be either positive or negative, as discussed in Section 3. Although there are a lot of uncertainties on the magnitude and sign of BC backscattering change, we estimate that the changes are roughly between 5.0 and +10.0 times. With the 5.0 BC backscattering decrease, BC forcing goes up by almost $40 \%$ (Table 4). This $40 \%$ increase is quite close to the $\mathrm{BC}$ forcing increase by the 1.9 time absorption increase. The 10-fold $\mathrm{BC}$ backscattering increase translates into a $60 \%$ reduction in $\mathrm{BC}$ forcing. When this 10 -fold $\mathrm{BC}$ backscattering increase is coupled with the 1.9 time absorption increase, BC forcing goes down by $14 \%$ (Table 4). Thus, in this case, coating ends up lowering $\mathrm{BC}$ forcing.

In the most likely scenario, thin and thick shells both exist and only a fraction of shells would have expanded existing scattering aerosols in the absence of BC. In this case, we approximate the absorption increase to be roughly $70 \%$ and the backscattering change to be roughly zero that leads to about a $40 \%$ enhancement of $\mathrm{BC}$ forcing. Jacobson $(2000,2001)$ calculated the forcing of externally mixed $\mathrm{BC}$ by taking the shells in coated $\mathrm{BC}$ and creating new scattering aerosols. Also, he treated $\mathrm{BC}$ as spherical in both externally and internally mixed cases. In this case, using the solid lines in Fig. 3a and b, we propose that absorption increases by about $70 \%$ and backscattering decreases slightly, thus amplifying BC forcing by only about $50 \%$. Because Jacobson simulated more than doubling of $\mathrm{BC}$ forcing by coating, we argue that he exaggerated the forcing amplification by simulating $\mathrm{BC}$ cores too small and shells too large. Small BC cores surrounded by large shells result in more than a doubling of absorption (Bond et al., 2006).

\section{Conclusion and discussion}

We have examined the effect of coating on $\mathrm{BC}$ absorption and backscattering and how the coating modifies BC forcing. The key findings are:

(1) The optical properties of BC aggregates are very sensitive to the size of monomers. Clusters with large and fewer monomers scatter and absorb much more than those with small and more monomers over realistic ranges of monomer size and cluster size.

(2) When integrated over a realistic size distribution, spherical BC particles absorb as much and scatter twice as much as BC aggregates.
(3) Coated BC absorbs up to 1.9 (1.8-2.1) times more than uncoated $\mathrm{BC}$ aggregates, when averaged over a realistic core size distribution. However, the coating effect on BC backscattering is extremely sensitive to shell size and how the shell material is distributed in the absence of $\mathrm{BC}$ core.

(4) The 1.9 time absorption increase amplifies global $\mathrm{BC}$ forcing by a factor of 1.4 .

(5) Because coating can increase or decrease BC backscattering significantly, coating may not necessarily increase $\mathrm{BC}$ forcing, despite the absorption enhancement.

Plenty of studies exist concerning the effect of coating on BC absorption (Bond et al., 2006; Moffet and Prather, 2009). This study is the first attempt to quantify the coating effect on BC backscattering. Although we have demonstrated that internal mixing by coating can significantly modify BC backscattering, we have failed to establish the sign of backscattering change. Is there any different way to assess this?

Aerosol models capable of simulating internal mixtures can perhaps investigate this issue by turning off $\mathrm{BC}$ emission. If aerosol backscattering decreases in no-BC atmosphere, then we know that internal mixture decreases $\mathrm{BC}$ backscattering significantly. However, aerosol models may overestimate or underestimate the thickness of shells, in which case, aerosol models can point to a wrong conclusion. Another way to investigate this issue is by looking at the relationship between total aerosol mass backscattering cross section and BC's contribution to total aerosol mass in ambient measurements. This method can bypass having to simulate correct shell thicknesses, although it suffers another problem, in that $\mathrm{BC}$ aerosols co-exist with organic carbon (OC) aerosols. Because aerosols rich in $\mathrm{BC}$ are also rich in $\mathrm{OC}$, it is difficult to isolate $\mathrm{BC}$ effect.

Quantifying the effect of coating on BC forcing has important implications. Ramana et al. (2010) demonstrated, with observations, that BC absorption efficiency is correlated with sulphate amount. If a higher ratio of sulphate to BC leads to more BC absorption, we need to know if this higher ratio also amplifies $\mathrm{BC}$ forcing. The conclusion to this question will influence the emission policies. Black carbon absorption efficiency may be related to $\mathrm{OC}$ because $\mathrm{OC}$ can also coat BC. Future studies are needed to address this issue.

\section{Acknowledgements}

The authors would like to thank Mr C. Liu and Prof. P. Yang of Texas A\&M for help with the BC cluster 
optical properties. They are also thankful to Prof. T. Bond of University of Illinois for discussing the definition of $\mathrm{BC}$ scattering in the context of internal mixture, and to Damien Decremer of GIST for his technical assistance. This work was supported by the National Research Foundation of Korea (NRF 2011-0005802).

\section{References}

Adachi, K., Chung, S. H. and Buseck, P. R. 2010. Shapes of soot aerosol particles and implications for their effects on climate. J. Geophys. Res. 115, D15206-D15209.

Alexander, D. T. L., Crozier, P. A. and Anderson, J. R. 2008. Brown carbon spheres in East Asian outflow and their optical properties. Science 321, 833-836.

Andreae, M. O. and Gelencsér, A. 2006. Black carbon or brown carbon? The nature of light-absorbing carbonaceous aerosols. Atmos. Chem. Phys. 6, 3131-3148.

Arola, A., Schuster, G., Myhre, G., Kazadzis, S., Dey, S. and co-authors. 2011. Inferring absorbing organic carbon content from AERONET data. Atmos. Chem. Phys. 11, 215-225.

Atwater, M. A. 1970. Planetary albedo changes due to aerosols. Science 170, 64-66.

Bond, T. C., Habib, G. and Bergstrom, R. W. 2006. Limitations in the enhancement of visible light absorption due to mixing state. J. Geophys. Res. 111, D20211-D20213.

Bond, T. C., Streets, D. G., Yarber, K. F., Nelson, S. M., Woo, J.-H. and co-authors. 2004. A technology-based global inventory of black and organic carbon emissions from combustion. J. Geophys. Res. 109, D14203-D14243.

Bond, T. C., Zarzycki, C., Flanner, M. G. and Koch, D. M. 2011. Quantifying immediate radiative forcing by black carbon and organic matter with the Specific Forcing Pulse. Atmos. Chem. Phys. 11, 1505-1525.

Brasil, A. M., Farias, T. L. and Carvalho, M. G. 2000. Evaluation of the fractal properties of cluster-cluster aggregates. Aerosol Sci. Technol. 33, 440-454.

Chakrabarty, R. K., Moosmüller, H., Arnott, W. P., Garro, M. A., Slowik, J. G. and co-authors. 2007. Light scattering and absorption by fractal-like carbonaceous chain aggregates: comparison of theories and experiment. Appl. Opt. 46, 69907006.

Chin, M., Ginoux, P., Kinne, S., Torres, O., Holben, B. N. and co-authors. 2002. Tropospheric aerosol optical thickness from the GOCART model and comparisons with satellite and sun photometer measurements. J. Atmos. Sci. 59, 461-483.

Choi, M. Y., Mulholland, G. W., Hamins, A. and Kashiwagi, T. 1995. Comparisons of the soot volume fraction using gravimetric and light extinction techniques. Combust. Flame 102, 161-169.

Chung, C. E., Ramanathan, V., Kim, D. and Podgorny, I. A. 2005. Global anthropogenic aerosol direct forcing derived from satellite and ground-based observations. J. Geophys. Res. 110, D24207-D24217.
Chýlek, P. and Wong, J. 1995. Effect of absorbing aerosols on global radiation budget. Geophys. Res. Lett. 22, 929-931.

Coz, E. and Leck, C. 2011. Morphology and state of mixture of atmospheric soot aggregates during the winter season over Southern Asia-a quantitative approach. Tellus 63B, 107-116.

Cressman, G. P. 1959. An operational objective analysis system. Mon. Wea. Rev. 87, 367-374.

Farias, T. L., Köylü, Ü. Ö. and Carvalho, M. G. 1996. Range of validity of the Rayleigh-Debye-Gans theory for optics of fractal aggregates. Appl. Opt. 35, 6560-6567.

Filippov, A. V., Zurita, M. and Rosner, D. E. 2000. Fractal-like aggregates: relation between morphology and physical properties. J. Colloid Interface Sci 229, 261-273.

Forrest, S. R. and Witten, T. A. Jr. 1979. Long-range correlations in smoke-particle aggregates. J. Phys. A: Math. Gen. 12, L109L117.

Foster, P., Ramaswamy, V., Artaxo, P., Berntsen, T., Betts, R. and co-authors. 2007. Changes in atmospheric constituents and in radiative forcing. In: Climate Change 2007: The Physical Science Basis. Contribution of Working Group I to the Fourth Assessment Report of the Intergovernmental Panel on Climate Change (eds S. Solomon, D. Qin, M. Manning, Z. Chen, M. Marquis and et al.). Cambridge University Press, Cambridge, United Kingdom and New York, NY, USA, 129-234.

Gyawali, M., Arnott, W., Lewis, K. and Moosmüller, H. 2009. In situ aerosol optics in Reno, NV, USA during and after the summer 2008 California wildfires and the influence of absorbing and non-absorbing organic coatings on spectral light absorption. Atmos. Chem. Phys. 9, 8007-8015.

Holben, B. N., Tanré, D., Smirnov, A., Eck, T. F., Slutsker, I. and co-authors. 2001. An emerging ground-based aerosol climatology: aerosol optical depth from AERONET. J. Geophys. Res. 106, 12067-12097.

IPCC. Climate change 2007. In: The Physical Scientific Basis. Contribution of Working Group I to the Forth Assessment Report of the Intergovernmental Panel on Climate Change. Cambridge University Press, Cambridge, UK and New York, NY.

Jacobson, M. Z. 2000. A physically-based treatment of elemental carbon optics: implications for global direct forcing of aerosols. Geophys. Res. Lett. 27, 217-220.

Jacobson, M. Z. 2001. Strong radiative heating due to the mixing state of black carbon in atmospheric aerosols. Nature 409, 695-697.

Katrinak, K. A., Rez, P., Perkes, P. R. and Buseck, P. R. 1993. Fractal geometry of carbonaceous aggregates from an urban aerosol. Environ. Sci. Technol. 27, 539-547.

Kim, D., Wang, C., Ekman, A. M. L., Barth, M. C. and Rasch, P. J. 2008. Distribution and direct radiative forcing of carbonaceous and sulfate aerosols in an interactive size-resolving aerosol-climate model. J. Geophys. Res. 113, D16309D16336.

Kirchstetter, T. W., Novakov, T. and Hobbs, P. V. 2004. Evidence that the spectral dependence of light absorption by aerosols is affected by organic carbon. J. Geophys. Res. 109, D21208D21212. 
Köylü, Ü. Ö. and Faeth, G. M. 1994. Optical properties of overfire soot in buoyant turbulent diffusion flames at long residence times. J. Heat Transfer 116, 152-159.

Li, H., Liu, C., Bi, L., Yang, P. and Kattawar, G. W. 2010. Numerical accuracy of "equivalent" spherical approximations for computing ensemble-averaged scattering properties of fractal soot aggregates. J. Quant. Spectrosc. Radiat. Transfer 111, $2127-2132$.

Liu, L. and Mishchenko, M. I. 2005. Effects of aggregation on scattering and radiative properties of soot aerosols. J. Geophys. Res. 110, 1-10.

Liu, L. and Mishchenko, M. I. 2007. Scattering and radiative properties of complex soot and soot-containing aggregate particles. J. Quant. Spectrosc. Radiat. Transfer 106, 262-273.

Liu, L., Mishchenko, M. I. and Arnott, W. P. 2008. A study of radiative properties of fractal soot aggregates using the superposition T-matrix method. J. Quant. Spectrosc. Radiat. Transfer 109, 2656-2663.

Liu, F. and Smallwood, G. J. 2010. Radiative properties of numerically generated fractal soot aggregates: the importance of configuration averaging. J. Heat Transfer 132, 1-6.

Moffet, R. C. and Prather, K. A. 2009. In-situ measurements of the mixing state and optical properties of soot with implications for radiative forcing estimates. Proc. Natl. Acad. Sci. USA 106, 11872-11877.

Moosmüller, H., Chakrabarty, R. K. and Arnott, W. P. 2009. Aerosol light absorption and its measurement: a review. $J$. Quant. Spectrosc. Radiat. Transfer 110, 844-878.

Myhre, G., Hoyle, C. R., Berglen, T. F., Johnson, B. T. and Haywood, J. M. 2008. Modeling of the solar radiative impact of biomass burning aerosols during the Dust and Biomass-burning Experiment (DABEX). J. Geophys. Res. 113, D00C16-D00C10.

Nyeki, S. and Colbeck, I. 1995. Fractal dimension analysis of single, in-situ, restructured carbonaceous aggregates. Aerosol Sci. Technol. 23, 109-120.

Ramana, M. V., Ramanathan, V., Feng, Y., Yoon, S. C., Kim, S. W. and co-authors. 2010. Warming influenced by the ratio of black carbon to sulphate and the black-carbon source. Nature Geosci. 3, 542-545.

Ramanathan, V. and Carmichael, G. 2008. Global and regional climate changes due to black carbon. Nature Geosci. 1, 221-227.

Ramanathan, V., Crutzen, P. J., Lelieveld, J., Mitra, A. P., Althausen, D. and co-authors. 2001. Indian Ocean Experiment: an integrated analysis of the climate forcing and effects of the great Indo-Asian haze. J. Geophys. Res. 106, 28371-28398.

Sato, M., Hansen, J., Koch, D., Lacis, A., Ruedy, R. and coauthors. 2003. Global atmospheric black carbon inferred from AERONET. Proc. Natl. Acad. Sci. USA 100, 6319-6324.

Schnaiter, M., Linke, C. Möhler, O., Naumann, K. H., Saathoff, H. and co-authors. 2005. Absorption amplification of black carbon internally mixed with secondary organic aerosol. J. Geophys. Res. 110, D19204-D19211.

Seinfeld, J. H. and Pandis, S. N. 1998. Atmospheric Chemistry and Physics: From Air Pollution to Climate Change. John Wiley \& Sons, NY.

Sorensen, C. M. 2001. Light scattering by fractal aggregates: a review. Aerosol Sci. Technol. 35, 648-687.

Sorensen, C. M. and Roberts, G. C. 1997. The prefactor of fractal aggregates. J. Colloid Interface Sci. 186, 447-452.

Textor, C., Schulz, M., Guibert, S., Kinne, S., Balkanski, Y. and co-authors. 2006. Analysis and quantification of the diversities of aerosol life cycles within AeroCom. Atmos. Chem. Phys. 6, 1777-1813.

Tumolva, L., Park, J. Y., Kim, J. S., Miller, A. L., Chow, J. C. and co-authors. 2010. Morphological and elemental classification of freshly emitted soot particles and atmospheric ultrafine particles using the TEM/EDS. Aerosol Sci. Technol. 44, 202215.

Van-Hulle, P., Weill, M. E., Talbaut, M. and Coppalle, A. 2002. Comparison of numerical studies characterizing optical properties of soot aggregates for improved EXSCA measurements. Part. Part. Syst. Charact. 19, 47-57.

Xu, Y. L. 1995. Electromagnetic scattering by an aggregate of spheres. Appl. Opt 34, 4573-4588.

$\mathrm{Xu}$, Y. L. 1996. Calculation of the addition coefficients in electromagnetic multisphere-scattering theory. J. Comput. Phys. 127, 285-298.

Xu, Y. L. 1997. Electromagnetic scattering by an aggregate of spheres: far field. Appl. Opt. 36, 9496-9508.

Xu, Y. L. and Gustafson, B. A. S. 2001. A generalized multiparticle Mie-solution: further experimental verification. $J$. Quant. Spectrosc. Radiat. Transfer 70, 395-419.

Xue, H., Khalizov, A. F., Wang, L., Zheng, J. and Zhang, R. 2009. Effects of dicarboxylic acid coating on the optical properties of soot. Phys. Chem. Chem. Phys. 11, 7869-7875. 